\title{
IMAGENS DA COREIA DO SUL NO PRISMA DA MODERNIDADE-MUNDO \\ UM ESTUDO SOBRE O POP COREANO NO CONTEXTO DA COPA DO MUNDO DE FUTEBOL DE 2014
}

Luã Ferreira Leal (Unicamp) e Michel Nicolau Netto (Unicamp)

Os megaeventos, em contexto de globalização, adquirem o estatuto de plataformas de divulgação de projetos vinculados às imagens dos lugares. Dessa forma, a produção da identidade nacional, relacionada ao aspecto comercial hoje adotado pela noção de nation branding, demonstra como os bens simbólicos passam a ser produzidos em um processo desterritorializado. Neste artigo, estudaremos a desterritorialização da produção da identidade nacional a partir do estudo de caso do gênero musical K-Pop no contexto da Copa do Mundo de 2014. Será demonstrado como diferentes instâncias, agentes do mercado de entretenimento e o Estado sul-coreano convergiram para a promoção do K-Pop como organizador de imagens da Coreia como polo cultural da modernidade-mundo.

MEGAEVENTOS, NATION BRANDING, IDENTIDADE NACIONAL, GLOBALIZAÇÃO, K-POP.

LEAL, Luã Ferreira e NETTO, Michel Nicolau. Imagens da Coreia do Sul no prisma da modernidademundo: um estudo sobre o pop coreano no contexto da Copa do Mundo de Futebol de 2014. Textos escolhidos de cultura e arte populares, Rio de Janeiro, v.13, n.1, p. 93-113, mai. 2016. 


\section{IMAGES OF SOUTH KOREA IN THE \\ PRISMA OF THE WORLD MODERNITY}

\section{A STUDY ON KOREAN POP IN THE CONTEXT OF THE WORLD CUP OF 2014}

Luã Ferreira Leal (Unicamp)

e Michel Nicolau Netto (Unicamp)

Mega-events, in the context of globalization, have acquired the status of platforms for the dissemination of projects linked to the images of places. In this way, the production of national identity, related to the commercial aspect adopted today by the notion of nation branding, portray how symbolic goods are produced in a deterritorialized process. In this article, we explore the deterritorialization of the production of national identity having as starting point the case study of the K-Pop musical genre in the context of the 2014 World Cup. We will show how different instances, entertainment market agents, and the South Korean state came together for the promotion of $K$-Pop as organizer of images of Korea as a cultural pole of the world modernity.

MEGA-EVENTS; NATION BRANDING; GLOBALIZATION; K-POP; NATIONAL IDENTITY.

LEAL, Luã Ferreira e NETTO, Michel Nicolau. Imagens da Coreia do Sul no prisma da modernidademundo: um estudo sobre o pop coreano no contexto da Copa do Mundo de Futebol de 2014. Textos escolhidos de cultura e arte populares, Rio de Janeiro, v.13, n.1, p. 93-113, mai. 2016. 


\section{INTRODUÇÃO}

Cinco dias antes da abertura da 20 edição da Copa do Mundo de futebol masculino, sediada no Brasil entre junho e julho de 2014, foi realizada o Music Bank World Tour no Rio de Janeiro, cidade em que também ocorreu a decisão do torneio organizado pela Fifa. No elenco de convidados para o Music Bank in Brazil constavam boy bands como INFINITE, SHINee, MBLAQ, CNBLUE, B.A.P e M.I.B, além da cantora Ailee. Nascida nos Estados Unidos e com carreira solo consolidada na Coreia do Sul, Ailee foi uma das protagonistas do momento de homenagem ao país anfitrião. Em um palco simulando o céu noturno salpicado de estrelas e com imagens do Cristo Redentor e do Pão de Açúcar nos telões, Ailee cantou o samba-exaltação "Aquarela do Brasil”, composto por Ary Barroso em 1939.

O Music Bank in Brazil (Figura 1) exemplifica como as fronteiras do mundo globalizado são reconstruídas por instâncias desterritorializadas de produção simbólica. Os megaeventos esportivos, os fluxos midiáticos e o mercado de entretenimento contribuem para a criação de nichos do mercado global de bens simbólicos. Desse modo, as atividades organizadas por representações diplomáticas e empresariais da Coreia do Sul durante a Copa do Mundo de 2014 servem para elucidar os mecanismos de construção e ressignificação da identidade nacional em um contexto de produção cultural desterritorializada.

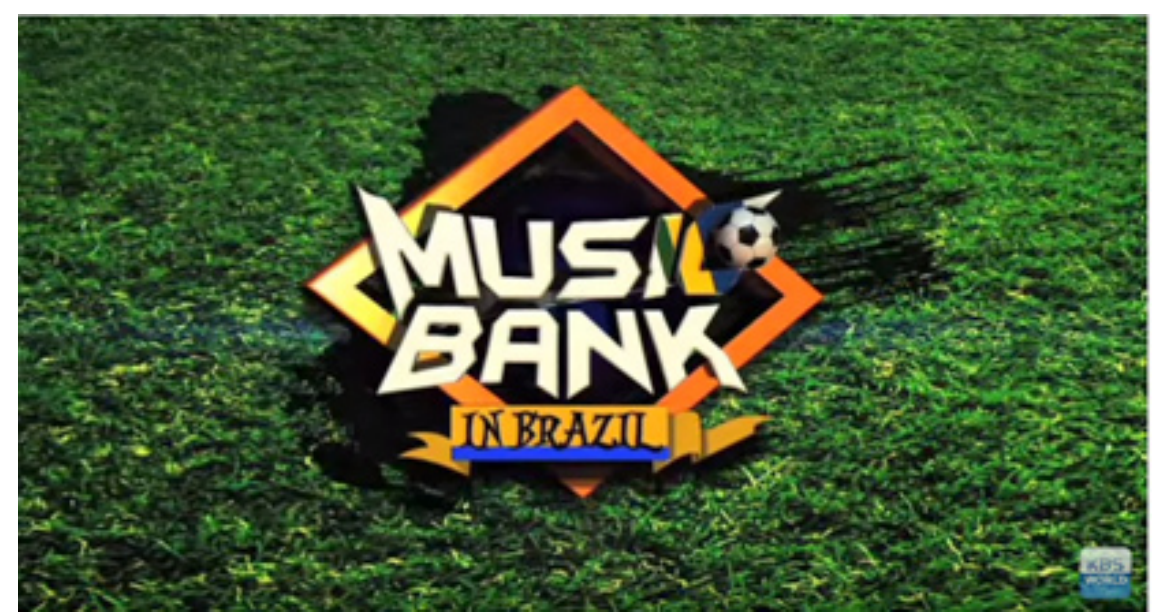

Figura 1: Music Bank in Brazil, um evento realizado pela emissora estatal KBS

Embora variados diagnósticos apontassem o possível desaparecimento de emblemas nacionais devido à globalização, na verdade, ocorreu uma ressemantização e reinscrição em um universo simbólico que transcende fronteiras dos Estados. Os suportes simbólicos para a veiculação de imagens da Coreia do Sul como país globalizado - em outros termos, ajustado às condições da modernidade- 
mundo (CHESNEAUX, 1996) - foram estruturados desde o final da década de 1980 e fortalecidos nas décadas seguintes com a inserção do país como promotor de megaeventos esportivos e difusor de produção cultural, processo que foi denominado Hallyu ou $K$-Wave.

Assim como a teia de Penélope, continuamente costurada mas nunca findada, os processos de desterritorialização e reterritorialização fundam novos padrões das relações em contexto de globalização. Para lidar com essa problemática, a música pop coreana e os megaeventos serão tomados neste texto como objetos de reflexão da desestabilização da representação identitária. Em reflexões sobre produção cultural, as abordagens normalmente se restringem aos países "centrais" como pontos de irradiação, o que cria um hiato na compreensão de outros trânsitos ou, seguindo a terminologia de Arjun Appadurai (1996), de outros fluxos transnacionais. A música pop representa, em parte significativa das análises como as de Simon Frith (2007), um elemento com grande potencial explicativo para abordar os modos de circulação cultural das indústrias culturais globais. A indústria fonográfica em meados do século XX tinha como público-alvo prioritário os consumidores da geração baby boomer, mas seu padrão de produção passou por diferentes reformulações nas últimas décadas. Desde o final dos anos 90 foram reorganizadas as relações entre gravadoras majors e indies, assim como a divisão internacional do mercado de música entre as responsáveis por hits globais e as que divulgam singles lançados em "mercados regionais".

O objetivo central deste artigo é abordar as identidades em jogo nas dinâmicas de desterritorialização da produção midiática. Para compreender onde incidem as imagens pelos prismas da modernidade-mundo, é necessário lidar com relações de força entre empresas e instâncias estatais, bem como com as assimetrias atreladas à globalização da economia e à mundialização da cultura (ORTIZ, 2003). Sem pretender analisar a formação dos gêneros musicais a partir dos signos sonoros, nosso foco recairá nos usos dos rótulos comerciais, que funcionam como atalhos para veiculação de bens em circuitos globais em megaeventos esportivos.

\section{CONSTRUÇÃO DA IDENTIDADE E MEGAEVENTOS NO CONTEXTO DE GLOBALIZAÇÃO}

Antes da realização da Copa do Mundo de Futebol de 2002, co-sediada por Coreia do Sul e Japão, o ministro coreano da Educação e Recursos Humanos afirmou que o evento constituía uma oportunidade para "construção da marca da Coreia" (HORNE, MANZENREITER, 2004, p. 192). Essa visão, de um lado, reafirmava uma política coreana que desde 1997, com a eleição do presidente Kim Dae-jung, 
assumiu o marketing do país como estratégia de Estado. Ainda no contexto da Copa do Mundo de 2002, o ministro do Comércio, Indústria e Energia "anunciou um plano ambicioso para elevar o reconhecimento internacional (e, assim, aumentar as exportações) dos produtos de marcas coreanas" (DINNIE, 2008, p. 872). Em 2007, com a eleição do presidente Lee Myung-Bak, antigo gerente da multinacional automotiva Hyundai, a administração coreana se tornou "obcecada com a imagem internacional da Coreia" (CHENG, 2008), instituindo, ainda em 2009, o Conselho Presidencial sobre Nation Branding. Dessa forma, ao mesmo tempo em que os megaeventos se tornavam alvo de desejo das autoridades coreanas, a noção de marca-país ocupava cada vez mais centralidade nas políticas públicas. Há, porém, outro lado dessa história, que se refere a um processo global.

Essa relação entre marca-país e grandes eventos não é específica da Coreia (embora sua voracidade, de fato, se destaque). Em 2007, durante a abertura da jornada para a Copa do Mundo de 2014, o presidente Lula afirmou que "com o Mundial, teremos a oportunidade de apresentar ao mundo um novo momento do Brasil" (Ivo, 2011, p. 47). O ex-presidente da Embratur e da SPTuris, ${ }^{1}$ Caio de Carvalho, em sua tese de doutorado, afirmou que o "retorno da imagem para o país, e para destinos turísticos como São Paulo que sediarão os jogos, é imensurável, dadas as proporções que o evento assume no conhecido 'país das chuteiras'" (CARVALHO, 2009, p. 199). Ciente da importância de um megaevento para a imagem (ou a "marca" do país), a Embratur elaborou uma nova edição de seu Plano Aquarela. Esse plano, lançado originalmente em 2005, além de ditar as bases do "marketing internacional" do país, tendo em vista o setor de turismo, definiu os elementos utilizados na elaboração da marca-país, até hoje utilizada pela Embratur, por alguns outros órgãos do governo federal e por algumas empresas brasilei-

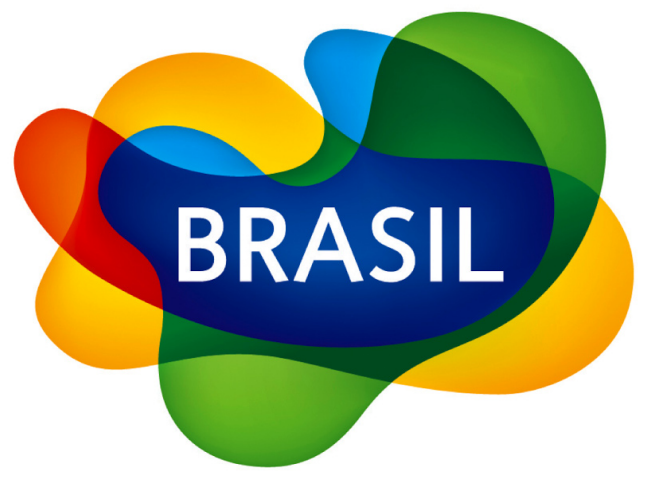

Figura 2. Marca Brasil

\section{Sensational!}


ras que operam no mercado global. (Figura 2) Em 2010, portanto depois da escoIha do Brasil como sede da Copa do Mundo e do Rio de Janeiro como cidade-sede dos Jogos Olímpicos de Verão, a edição do Plano Aquarela tinha seu foco, justamente, nesses eventos, assim entendidos pelo então ministro do turismo brasileiro como a oportunidade de projetar o país no mundo, de construir uma imagem de modernidade, competência para receber grandes eventos, aliada às já conhecidas belezas naturais e culturais do país, farão do Brasil um dos principais destinos turísticos do mundo até 2020. (EMBRATUR, 2010, p. 5)

A relação entre megaeventos e promoção da imagem dos países se torna uma máxima hoje. Todos os países ou cidades que sediam um megaevento o justificam apelando para a "oportunidade" de promover sua imagem; todos os países ou cidades que buscam a promoção global de suas imagens (desenvolvem um projeto de branding, como hoje se diz) competem pela atração dos megaeventos.

Antes de continuar, é preciso ter uma definição minimamente precisa sobre megaeventos. A melhor disponível foi elaborada por Maurice Roche (2000, p. 1), para quem

Megaeventos são eventos culturais (incluindo comerciais e esportivos) de larga escala que possuem um caráter dramático, um apelo popular de massa e um significado internacional. Eles são tipicamente organizados por combinações variáveis de organizações governamentais nacionais e não governamentais internacionais e assim pode-se dizer que possuem elementos importantes nas versões "oficiais" da cultura pública.

Por essa definição, três são seus tipos mais puros: as Expos Mundiais (que ocorrem desde 1851), Jogos Olímpicos de Verão (desde 1896) e a Copa do Mundo de Futebol (desde 1930). São, portanto, eventos que remontam à ritualização das nações e da modernidade, algo presente até os dias de hoje. Contudo, na contemporaneidade, deve-se acrescentar a essa definição de Roche duas outras características que se aplicam, especialmente, aos dois eventos esportivos citados: eles são predominantemente acontecimentos midiáticos; e seu significado não é simplesmente internacional, mas global. O primeiro elemento se explica pelo fato de que o principal destino de toda a organização dos eventos é sua difusão pela mídia, quer dizer que desde as cerimônias (de abertura e de encerramento) até as competições, tudo é pensado em primeiro lugar como uma forma de espetáculo midiático (KELLNER, 2003). Isso é uma óbvia consequência do fato de que é ínfima a quantidade de pessoas assistindo aos eventos in loco em comparação com a quantidade de pessoas que o fazem através de mídias. Isso, po- 
rém, também se dá porque o espetáculo midiático é um espetáculo de imagens comerciais, de empresas globais, que se interessam pelo total controle do que é visto e ouvido pelos espectadores como forma de promoção de suas marcas. Um espetáculo midiático é mais fácil de ser controlado, em termos das imagens que se propagam, do que um espetáculo imediato.

O segundo elemento, o fato de o impacto ser mais bem caracterizado como global do que internacional, decorre, em primeiro lugar, da abrangência. A Copa de 2014 foi transmitida para 239 países e territórios do mundo (contra 36, em 1966); a Copa de 2010 teria sido assistida (em algum de seus momentos) por 3,2 bilhões de pessoas, ou seja, quase a metade da população mundial (TOMLINSON , 2014). Dessa forma, os megaeventos não atingem apenas as populações daqueles países diretamente participantes (as 32 nações de uma Copa do Mundo), mas pessoas de todo o mundo. Aqui, porém, não se trata apenas de abrangência, mas de internalização dos megaeventos no cotidiano de todas as pessoas: eles se tornam parte de um espaço comum que passamos a habitar, o mundo. Essa globalidade também se confirma porque boa parte das estruturas envolvidas nos megaeventos são multilocalizadas. Não se trata mais apenas da relação entre um órgão internacional (Fifa e Comitê Olímpico Internacional) e um Estado-nação (que o hospeda). As empresas de transmissão, as redes de TV, os arquitetos dos estádios, as empresas construtoras, as cadeias de hotéis que se abrem para receber os turistas, os discursos que embasam os jogos (tanto os otimistas - como legados ambientais, crescimento econômico, etc. - quanto os pessimistas, como privatização do espaço urbano, remoção injusta de famílias, gastos injustificados, etc. - são globais), os turistas estão espalhados por vários países, o que faz com que de alguma forma o mundo inteiro se envolva nesses megaeventos.

É justamente esse alcance midiático global dos megaeventos que justificaria a noção de que eles se tornam plataforma para a promoção da imagem dos países que os recebem. A lógica se refere ao fato de que países competem em um espaço altamente povoado por uma infinidade de imagens que circulam globalmente nas mídias e que buscam, como os países, atrair a atenção. Os megaeventos conseguiriam, então, destacar uma nação (não apenas dentre outras, mas dentre outras tantas imagens), em um período curto de tempo, de modo incomparável. A questão não é criticar essa assertiva, mas refletir sobre outro aspecto. A promoção se refere a uma forma de construção e ressignificação das identidades nacionais, em um processo que se define, em primeiro lugar, pela homologia entre identidade e marca-país; em segundo lugar pela dinâmica global de sua produção. 
Em um balanço sobre o projeto de marca da Coreia do Sul em 2008, lê-se uma definição concisa sobre nation branding:

Afinal, o que é nation branding? Em 1996, o consultor britânico Simon Anholt cunhou a expressão nation brand ou nation branding para se referir à maneira como os países são percebidos por outros. O processo de nation branding é um projeto de múltiplas fases que envolve ao mesmo tempo esforços focados interna e externamente. A primeira fase envolve a obtenção de melhor compreensão das fraquezas e fortalezas do país para identificar-lhe a essência e se tornar capaz de usar melhor os recursos nacionais. Essa fase de descoberta então serve para informar qual deveria ser a nova imagem e identidade do país, jogando luz em seus atributos que podem ajudá-lo a se destacar dos outros. A segunda fase envolve a comunicação dessa nova identidade e imagem para o mundo a fim de ajudar a reformar as percepções externas do país de uma forma controlada e sistemática. O nation branding, como um todo, é o esforço de cada nação para formar ativamente ou controlar opiniões internacionais sobre a marca do país para que elas reflitam seus ativos centrais e atributos políticos, econômicos e culturais (CHENG, 2008, p. 77).

Dessa definição, gostaríamos de destacar alguns pontos. Inicialmente, há a presunção de que a nação se tornou um ativo, ou seja, um elemento relacionado a atribuição de valor e a geração de capital. Isso significa que a nação, enquanto símbolo, não se relaciona apenas a uma dimensão política (formação territorial, definição de limites do poder do Estado, atribuição de direitos e cidadania) ou cultural (formação de uma comunidade imaginada, atribuição de características a um povo, etc.), mas a uma dimensão de mercado. De um lado, a nação poder atribuir valor aos objetos. Estamos aqui na esfera de um tipo de atribuição de valor que Scott Lash e John Urry (1994) chamaram de estético. Com isso, entende-se que o valor de uma mercadoria pode ser atribuído, centralmente, por seu elemento estético (como o design). As identidades (nacionais, mas também étnicas em geral, como se nota pelo comércio de artesanato de arte africana (STEINER, 1994), pelas pinturas e turismo indígena, etc.) se tornam esse elemento estético que atribui valor às mercadorias. Dessa forma, o valor de um produto incorporado de "Brasil" possui um valor, guardadas todas as outras variáveis iguais, diferente de outro incorporado de "Alemanha". Se será maior ou menor vai depender da área comercial em que o produto se insere. Passam-se aqui os processos que John e Jean Comaroff (2009) chamaram de incorporação e comodificação das etnias. 
De outro lado, mas como consequência disso, a nação pode ser pensada como detentora de valor. O consultor britânico Simon Anholt criou um ranking no qual busca calcular o valor das marcas das nações. Passa-se como se as nações, tal como a marca de produtos, pudessem ser licenciadas, e se calcula quanto custaria esse licenciamento. O ranking de Anholt talvez seja o mais prestigiado (por governos e por empresas), mas não é o único. Em conjunto com o Samsung Economic Research Institute, o Conselho Presidencial sobre Nation Branding da Coreia do Sul criou seu próprio índice para calcular o valor das marcas nacionais no mundo e, assim, perceber o posicionamento coreano (DONG-HUN, 2011, p. 125). Por meio desses rankings, as nações podem se comparar entre si como unidades competitivas no mercado global; mais ainda, podem mesmo se comparar a outros "produtos", razão pela qual elas ocupam hoje os espaços de promoção que estavam reservados a produtos. ${ }^{2}$

Nesse ambiente de mercado, então, a marca da nação é produzida. A imagem promovida pelo branding seleciona apenas os elementos que possuem prestígio no mercado global. Trata-se, portanto, de uma nova articulação da identidade nacional instituída e da criação de novos elementos que passam a formar essa identidade. Em ambos os casos, o que importa não é a formação do caráter nacional, para lembrarmos de um velho termo, mas a formação de um asset valoroso no mercado global. Simon Anholt (2007, p. 75) é bastante direto: “identidade nacional e marca-nação são virtualmente a mesma coisa: marca-nação é a identidade nacional tornada tangível, robusta, comunicável e, sobretudo, útil". O ponto a se destacar é que só se tornam comunicáveis e úteis aqueles aspectos, discursados como nacionais em uma marca, que tenham interesse no mercado.

O processo que transforma identidade em marca, forma que prevalece na promoção dos países nos megaeventos, é um processo estratégico, embasado em uma suposta racionalidade determinada pela lógica do mercado. Ao mesmo tempo, é um processo que se faz em espaços que não se resumem às fronteiras do nacional. Em outras palavras, a marca das nações está sendo produzida em um espaço global, no qual as nações se tornam elementos de uma cultura global predominantemente de consumo. Separemos os elementos dessa afirmação.

Aquilo que se define como nacional está sendo praticado em lugares distantes daqueles tradicionalmente vistos como os limites do Estado-nação. Está sendo praticado nas mídias globais (em filmes, em minisséries, em programas jornalísticos, etc.); nas propagandas de produtos que usam a nação como forma de atribuição de valor; nas ações do Estado em eventos internacionais; nos grupos de imigrantes, que formam comunidades nas quais a ritualização da nação de origem se torna modo de coesão social; nas imagens turísticas, produzidas por 
operadoras, agências e órgãos oficiais de turismo, que circulam o globo criando imagens sobre os lugares; nos próprios atos dos turistas que vão a outros lugares, mas neles encenam suas próprias noções da nação. Os megaeventos, e aqui reside a importância para essa forma de produção da nação, não apenas reúnem todos esses elementos de uma produção desterritorializada da nação, como os colocam em dimensão mais ampla.

Dessa forma, temos que a nação está sendo produzida de forma multiterritorializada e diversificada. Como consequência, a nação não é mais um elemento somente do imaginário nacional, mas da cultura global. Afirmamos isso no sentido dado por Mike Featherstone (1999) ao termo, que se relaciona diretamente com o conceito de mundialização de Renato Ortiz (2003) e de imaginário global de Arjun Appadurai (1996). A cultura global não é um todo no qual as diferenças desaparecem, mas é justamente a formação de uma série de diferenças que se tornam compartilhadas - assimetricamente - pelos habitantes do globo. Em outras palavras, as identidades brasileira ou coreana se tornam elementos da cultura global, variações dessa cultura, apropriadas por um brasileiro, um coreano, um alemão, um francês, etc. Por isso, a culinária japonesa não deixa de ser japonesa ainda que seja hoje integrante de qualquer promoção turística da cidade de São Paulo; ou uma banda de K-Pop com integrantes nascidos em outros países não deixa de ser adjetivada como coreana. Coreia, Brasil, Japão (ou Seul, São Paulo, Rio de Janeiro, Tóquio) são parte do imaginário global, parte das imagens que as pessoas compartilham pelo mundo.

\section{DESTERRITORIALIZAÇÃO E DESNACIONALIZAÇÃO}

Podem ser analisados dois níveis integrados de circulação internacional de bens, serviços e de imagens da Coreia do Sul: de um lado, o projeto estatal de inserção global do país, quer no sistema universitário ${ }^{3}$ (a instalação de universidades e a atração de estrangeiros para seus polos de tecnologia), quer na atração de turistas e investimentos (a Copa do Mundo de 2002, os Jogos de Inverno de 2018, entre outros megaeventos esportivos); de outro, a capacidade de empresas de tecnologia da informação, gravadoras, emissoras de televisão e de bens de consumo (Hyundai, Kia, KT Corporation, Samsung e LG, por exemplo) estabelecerem redes com grande capilaridade internacional. Em diferentes circunstâncias, as imagens da Coreia do Sul são construídas de modo que representam um país capacitado para ser global, cuja síntese seria encontrada na ideia de "Global Korea".

Como a produção cultural é transpassada por fluxos internos e externos às fronteiras, o espaço nacional de uma cultura tida como específica é redefinido mediante a criação de novas formas de veiculação midiática. Desterritorializado, 
consideramos importante frisar, é diferente de algo desnacionalizado. O elemento nacional permanece no universo simbólico e pode ser desterritorializado - e, por conseguinte, reterritorializado - quando representado a partir de imagens que circulam sem fixação circunscrita ao Estado-nação.

Desenvolve-se, assim, a noção de construção das identidades no contexto da globalização, cujas forças entre agentes e instâncias em disputa estão fortemente orientadas para o gerenciamento de imagens no âmbito da circulação midiática de símbolos representativos. No universo simbólico da modernidademundo, além dos significantes que demarcam a "invenção das tradições nacionais" - bandeira, hino, selos e brasões -, surgem novos elementos que atribuem sentido a narrativas hierarquizantes a respeito do lugar de cada país em contexto de globalização. As novas referências nacionais como nation branding não precisam estar atreladas a um espaço circunscrito, com fronteiras bem delimitadas como o Estado-nação, mas podem estar articuladas a marcas de empresas, circulando por fluxos midiáticos e divulgadas em arenas globais que não coincidem com a sociedade nacional referida simbolicamente.

As representações de elementos nacionais encontram ressonância ou retradução quando alinhavadas com as marcas transnacionais das companhias patrocinadoras dos megaeventos: Adidas, Coca-Cola e Hyundai, por exemplo. A relação fica mais evidente quando observamos os trânsitos e as trajetórias de chairmen de conglomerados e dirigentes esportivos. Citaremos um exemplo: antes de assumir a presidência da Korea Football Association (KFA), Chung Mong-Gyu, no cargo desde 2013, também teve passagens como dirigente de clubes de futebol e de associações internacionais como a East Asian Football Federation, além de ter carreira como executivo da Hyundai na década de 1990.

Os megaeventos no século XXI tornaram-se vitrinas ou plataformas de divulgação dos países tidos como "emergentes", sobretudo no que concerne a competições esportivas: China, África do Sul, Rússia e Brasil, além dos aspirantes a lugares privilegiados de atribuição de prestígio como Qatar, Emirados Árabes Unidos e Azerbaijão. Assim como na Coreia do Sul, ${ }^{4}$ agentes e instâncias desses países almejam, com apoio de empresas e entidades transnacionais, a melhor inserção possível de suas imagens no "concerto" global das nações. Desde 2002, KPop (Korean Pop) foi inserido como elemento de difusão da representação imagética, atrelado a eventos esportivos na Coreia do Sul. Na cerimônia de abertura da Copa do Mundo, realizada no Seul World Cup Stadium, após a execução da canção folclórica "Arirang" teve início a apresentação do jingle oficial "Let's together now" com as "vozes da Coreia do Sul e do Japão" formadas por artistas de 
música pop: a dupla masculina Chemistry e a cantora Sowelu do Japão; a dupla masculina Brown Eyes e a cantora Lena Park da Coreia do Sul.

Sem adentrar os debates sobre a definição de gêneros musicais, podemos apontar que K-Pop é um rótulo aplicado a diferentes produções gerenciadas por empresas de entretenimento que, desde o início dos anos 2000, ganharam força na competição entre produtores de bens culturais. Na condição de categoria que vende em diferentes nichos e níveis do mercado midiático transnacional, KPop permite o cruzamento de várias formas de apresentar a Coreia do Sul como país globalizado.

Entre outras atividades de marketing durante a Copa de 2014, a Hyundai patrocinou as arenas de shows denominadas Hyundai Fan Parks nas cidades de Berlim, Madri, Turim, Sarajevo e Sidney. Em Seul, esse evento, financiado por uma das patrocinadoras oficiais do mundial de futebol masculino, foi realizado para que o público acompanhasse as partidas da seleção sul-coreana na Hyundai Fan Park Gangnam. A torcida oficial Red Devil, cujo mascote é um demônio da guerra da mitologia sino-coreana conhecido como Chiwoo, também ajudou na promoção desses eventos que teriam reunido cerca de 100 mil pessoas no jogo de estreia da seleção sul-coreana. ${ }^{5}$ No mesmo dia, o show realizado na Gwanghwamun Plaza contou com uma das principais estrelas do mercado de entretenimento sul-coreano: o rapper Psy. Nos dias 23 e 27 de junho - devido ao fuso horário os jogos foram transmitidos ao vivo durante madrugadas e manhãs na Coreia do Sul -, alguns K-Idols integrantes de girls groups e boys bands fizeram apresentações até o início das partidas. Na segunda partida da seleção sul-coreana, no dia 23 de junho contra a seleção argelina, o Hyundai Fan Park Gangnam recebeu girls groups convidados AOA, T-ara e Sistar com transmissão ao vivo da emissora televisiva SBS Sports, canal da rede Seoul Broadcasting System (SBS), e a marca esportiva Adidas ${ }^{6}$ realizou o evento Adidas All In Arena, com apoio promocional da EA Sports ${ }^{\mathrm{TM}}$ FIFA ONLINE 3 e a participação do grupo 2 NE1 ${ }^{7}$.

Em maio de 2014 houve o lançamento do álbum We Are the Reds, ${ }^{8}$ coletânea de dez músicas compostas para incentivar a campanha da seleção durante a Copa. A primeira faixa, "Song of Fighting Spirit", foi cantada por Ailee, e o álbum conta ainda com os singles "Spread the wings of Victory" gravado pelo grupo AOA, "To the Victory 2014" por Transfixion \& Mina, "Go Reds GO" por Tiny-G, entre outros. Com exibição de cheerleaders, público portando bandeiras da Coreia e $\mathrm{K}$-Idols com diversas referências à torcida pela seleção (como adereços relacionados aos Red Devils, chifres, bolas de futebol e uniformes oficiais), a emissora MBC transmitiu o especial 2014 World Cup Cheering Show, com apresentação de Kim Jung Geun, Eun Ji (integrante do grupo Apink) e Lizzy (do grupo After School e da 
subunidade Orange Caramel). O programa, exibido no mesmo mês de lançamento de We Are the Reds, teve em sua lista de convidados girls groups - Orange Caramel, Apink, Crayon Pop e Girls Day - e boy bands - Block B, a subunidade EXO-K e VIXX - cantando seu repertório de divulgação regular, mas serviu também para que AOA e Ailee lançassem as músicas gravadas do álbum mencionado.

As emissoras de televisão concorrem em um mercado bastante circunscrito de celebridades da música e da dramaturgia na Coreia do Sul. As atividades esportivas também são alvo de ações de marketing, sobretudo o beisebol e o futebol. Apesar da predominância da emissora KBS, as redes de relação entre empresas produtoras dos artistas em parceria com produtores de programas televisivos aumentam o alcance de K-Pop como emblema sul-coreano da globalização. Devido à Copa do Mundo de 2014, a MBC realizou episódio especial de seu programa Running Man com o jogador de futebol Park Ji-Sung e Leo, integrante da boy band VIXX, assim como produziu o Word Cup Cheering Show, ao passo que o Music Bank World Tour in Brazil foi promovido pela KBS. ${ }^{9}$

Desde 2011 o Music Bank deixou de ser apenas um programa com apresentações de grupos musicais nos estúdios ou, em algumas ocasiões, em concertos ao ar livre na Coreia do Sul para circular em outros países. Com a promoção do Music Bank World Tour, a KBS estimula a promoção de shows em arenas esportivas fora da Coreia como forma de divulgação dos grupos de K-Pop. Diferente dos episódios regulares - com competição pelo primeiro lugar do K-Chart após a contagem de índices que somam a venda de álbuns, fonogramas digitas, votos do público e quantidade de apresentações na emissora KBS -, o Music Bank World Tour não tem "ranqueamento", mas uma seleção de alguns dos principais nomes do mercado de entretenimento sul-coreano. A primeira edição foi realizada em Tóquio em 2011, depois o Music Bank World Tour percorreu Paris, Hong Kong, Viña del Mar, Jacarta, Istambul, Rio de Janeiro, Cidade do México e Hanói. Nas últimas edições, em cada país anfitrião havia uma empresa sul-coreana responsável por financiar a realização dos shows. Com fábrica instalada em Piracicaba (SP) desde 2011, a Hyundai Motor, montadora fundada na Coreia do Sul e uma das parceiras da Fifa na realização da Copa do Mundo de 2014, foi a principal empresa patrocinadora do Music Bank in Brasil.

No início da transmissão do Music Bank World Tour in Brazil, o vídeo de introdução apresentou imagens da cidade do Rio de Janeiro, com alguns letreiros informativos sobre a "cultura" do Brasil, sintetizada pelas palavras-chave festa, futebol e carnaval. De acordo com a vinheta, a praia e o sol intenso seriam marcas da natureza no lugar com pessoas sorridentes e com boa energia, onde o futebol é tudo. O letreiro inicial informou que pela primeira vez o país receberia um 
concerto de World K-Pop daquela magnitude. Ao fundo do logotipo dessa edição especial, nas cores verde, amarelo e azul, o gramado e uma bola de futebol revelam a direta relação da Copa do Mundo com a escolha do Brasil para sediar a sétima edição do Music Bank World Tour.

Formaram o quarteto de apresentadores Jung Ji Won, comunicadora da emissora KBS, Lee Joon do grupo MBLAQ, Jung Yong-hwa do CNBLUE e o cantor e ator brasileiro Fiuk. Realizado na HSBC Arena, construída no Rio de Janeiro para os Jogos Pan-Americanos de 2007, o show seguiu o formato das edições anteriores: após a saudação inicial dos K-Pop Stars, houve uma performance introdutória relacionada ao país anfitrião. A abertura teve como tema "Batucada Brasileira" e, como em todos os programas da Coreia do Sul, letreiros sempre explicam algo a respeito da música executada: o "samba" foi definido como dança latina com ritmos fortes, característica do carnaval brasileiro. Após a performance com passistas no palco, os artistas integrantes das boys bands e Ailee ${ }^{10}$ cantaram juntos "Vou deixar", do conjunto Skank. O letreiro na parte inferior da tela informa que a balada de pop rock foi gravada originalmente pela banda no álbum Cosmotron em 2003 e, por sugerir que cada um deve levar a vida como quiser, seria uma espécie de "hino" do espírito brasileiro. Também em 2014, no mês de outubro, ocorreu a edição na Cidade do México (na Arena Ciudad de México, estádio construído em 2012) e, para homenagear o país anfitrião na abertura, foi executada "La Bamba" do grupo Los Lobos, definido pelo letreiro como hino não oficial do país. Um mês depois do Music Bank in Mexico seria lançado o canal KBS World Latino, com escritório sediado em Los Angeles, com programas de variedades e doramas legendados em espanhol. ${ }^{11}$

Após celebração com as bandeiras de todas as seleções da Copa exibidas nos telões, algumas bolas arremessadas por K-Idols para o público, exposição de adereços de torcidas e bonecos da mascote oficial Fuleco, teve início o Special Stage To Brazil: os cantores Tae-min da banda SHINee, Jonghyun da CNBLUE e Sung-kyu da INFINITE cantaram "Girl from Ipanema", com versos em inglês e português, e Ailee entoou o samba-canção de Ary Barroso "Aquarela do Brasil". Com legenda em inglês, coreano (hangeul) e português, a exibição do Music Bank in Brazil está disponível no canal KBS World TV do Youtube desde julho de $2014 .^{12}$ De acordo com letreiro da transmissão, o samba-canção de Ary Barroso, definido como segundo hino nacional brasileiro, refletiria a beleza do cenário brasileiro, o povo e a cultura. Após Special Stage To Brazil, a apresentadora Jung Ji Won passou a trajar uma camisa customizada da torcida oficial da seleção ("Korea Legend" com a sigla de seu nome JJW), enquanto Lee Joon e Jung Yong-hwa portavam bandeiras e cachecóis da Coreia e do Brasil. 


\section{CONCLUSÃO}

Os exemplos deste artigo apontam para a diferença entre desnacionalização, que significaria exclusão de referenciais nacionais, e desterritorialização: as formas de simbolizar determinada "identidade", em contexto de globalização, não estão circunscritas ao gerenciamento exclusivo dos Estados nacionais. Os megaeventos, sobretudo quando permeados por uma trilha sonora que remete a produtos culturais de exportação como K-Pop, ${ }^{13}$ servem como vitrinas para exposição do ajustamento de cada país ao concerto globalizado que envolve instâncias estatais, conglomerados midiáticos e empresas de tecnologia e bens de consumo. Abordar a desterritorialização como vetor da globalização nos permite compreender algumas das diferentes formas de circulação de bens culturais como Ailee cantando "Song of Fighting Spirit", faixa do álbum We Are the Reds no World Cup Cheering Show da MBC, e sua interpretação de "Aquarela do Brasil" no Music Bank World Tour da emissora KBS. Durante as edições do Brasil e do México, além de apresentar vídeos sobre o país anfitrião e com informações acerca da Coreia do Sul ("o coração do K-Pop", de acordo com o vídeo promocional exibido no Rio de Janeiro), o Music Bank funciona como polo de atração de vendedores de diferentes produtos sul-coreanos que serão apresentados aos fãs de K-Pop. Na edição no Rio de Janeiro, a onipresença da marca Hyundai indica como bens de consumo e serviços relacionados com o slogan "Imagine your Korea" (Figuras 3 e 4) convertem o K-Pop em cartão de visitas de atividades de delegações diplomáticas e empresarias, além de trilha sonora de megaeventos esportivos. ${ }^{14}$

O exemplo sul-coreano, conforme abordagem de Shim (2006), explicita com clareza quais vetores dão suporte à "produção" e à "reprodução da ordem social globalizada": instâncias estatais e corporações transnacionais (ORTIZ, 2003, p. 97). O universo simbólico ao qual é referida a nation branding serve como horizonte em que as formas de consumo podem ser orientadas nos mercados de bens desterritorializados. Nos eventos transnacionais as fronteiras imaginárias são redesenhadas, mas com tamanha porosidade, que embaralham aquilo que seria definido como interno ou externo.
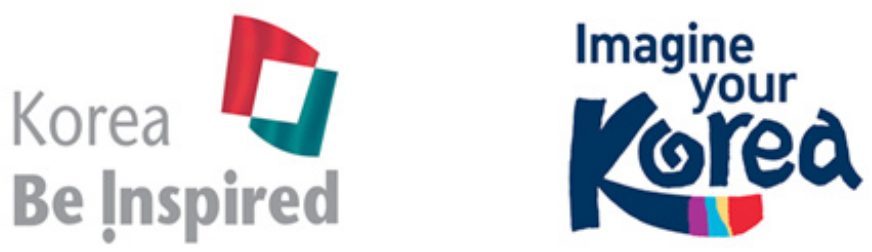

Figuras 3 e 4: O logotipo e o slogan da marca da Coreia do Sul foram reformulados e lançados em 2014 pela Korea Tourism Organization (KTO) 
A Embaixada da República da Coreia no Brasil promoveu durante 2014 diferentes concursos e editais como o Programa de Apoio a Eventos de Cultura Coreana, uma linha de financiamento para divulgação de K-Pop e K-Dramas. As formas de mensuração do impacto das vendas dessas imagens são geridas por organizações como Corea Image Communication Institute (Cici), fundada em 2003 sob responsabilidade do Ministério de Relações Exteriores e Comércio e atualmente com patrocínio da Samsung Electronics, Asiana Airlines, Korean Air, entre outras empresas. Conforme aponta o discurso da presidente da Cici, a professora Choi Jungwha, da Hankuk University of Foreign Studies: “Understanding Korea's politics, economy, society, culture, science and technology within the framework of globalization is not only essential in external relations but also to establish our identity and alleviate friction". ${ }^{15}$ Modernidade e tradição, portanto, são vinculadas para "vender" representações da Coreia do Sul pelos agentes da diplomacia cultural, como a estratégia de divulgação do Han Style (ELFVING-HWANG-HWANG, 2013; CHENG, 2008, p. 81).

A desterritorialização do K-Pop, paradoxal tendo em vista o próprio sentido do uso do gentílico, demonstra como as identidades nacionais são construídas em fluxos globais, que, contudo, se territorializam em determinados lugares. Assim como as cidades globais analisadas por Saskia Sassen (2007), propomos aqui que os megaeventos transnacionais são também lugares de localização da globalização. É evidente que há uma tendência histórica de os megaeventos coincidirem com as cidades globais. Contudo, cada vez mais os vemos serem sediados em cidades de porte menor, como Sochi, Kazan, Gwangju e PyeongChang -, o que revela, de um lado, suas estratégias de galgar status semelhante ao das cidades globais, mas, de outro, que os megaeventos tornam móveis os elementos produtivos da globalização e, dessa forma, ainda mais globais. As análises que fizemos aqui em referência ao K-Pop e a identidade sul-coreana revelam isso.

Mas não é só isso. Como os eventos se territorializam em certos lugares, há uma frequente produção de imagem desses lugares nos eventos, que atravessam as identidades articuladas. Assim, da mesma forma que o Music Bank World Tour in Brazil, ocorrido no contexto da Copa do Mundo de 2014, foi cenário de produção da identidade sul-coreana, ao articular cores, músicas, imagens atreladas ao Brasil, e difundi-las pelo mundo, também a identidade brasileira foi ressemantizada, notadamente em torno de seus mais óbvios clichês.

As competições esportivas, portanto, servem como vitrinas que proporcionam divulgação das marcas nacionais, as quais também são veiculadas em shows musicais e campanhas de incentivo ao turismo. A globalização cria novos contornos e redefine fronteiras. A representação sobre os países já não está mais 
circunscrita ao Estado nacional, ou seja, é possível pensar a desterritorialização do nacional devido à perda do monopólio estatal sobre representações de símbolos nacionais.

\section{REFERÊNCIAS BIBLIOGRÁFICAS}

ANHOLT, Simon. Competitive Identity: the new brand management of nations, cities and regions. New York: Palgrave Macmillian, 2007.

APPADURAI, Arjun. Modernity at Large. Minneapolis: University of Minnesota, 1996.

CARVALHO, Caio L. Políticas públicas no turismo brasileiro: a cidade de São Paulo e a construção de sua identidade turística. São Paulo: USP, 2009.

CHENG, L.-C. The Korea Brand: the cultural dimension of South Korea's branding project in 2008. Disponível em US-Korea Institute at SAIS: www.uskoreainstitute.org, 2008. Acesso em 28/9/2015.

CHESNEAUX, Jean. Modernidade-mundo. Petrópolis: Vozes, 1996.

COMAROFF, J. L.; COMAROFF, J. Ethnicity, Inc. Chicago/London: The University of Chicago Press, 2009.

DINNIE, Keith. Nation-branding issues and initiatives. In: DINNIE, K. Nation branding: concepts, issues, practices. Amsterdam: BH, 2008.

DONG-HUN, L. Korea's National Brand in 2010. SERI Quarterly, 4 (2), p. 125-133, 2011.

EMBRATUR. Plano Aquarela 2020 Marketing Turístico Internacional do Brasil, 2010.

ELFVING-HWANG, Joanna. South Korean Cultural Diplomacy and Brokering "KCulture" Outside Asia. Korean Histories, v. 4 (1), p.14-26, 2013.

FEATHERSTONE, Mike. Cultura Global: Introdução. In: FEATHERSTONE, Mike (Org.). Cultura Global: nacionalismo, globalização e modernidade (p. 7-23). Petrópolis: Vozes, 1999.

FRITH, Simon. Taking popular music seriously: selected essays. Hampshire: Ashgate Publishing, 2007.

HORNE, J. D.; MANZENREITER, W. Accounting for mega-events: forecast and actual impacts of the 2002 Football World Cup Finals on the host countries Japan/Korea. Internacional Review for the Sociology of Sport, 39 (2), 187-203, 2004.

IVO, A. B. Una nueva copa en un nuevo país: intervenciones urbanas y creación de ciudades para el mundial de fútbol Brasil 2014. Bitacora, 18, p. 39-54, 2011.

KELLNER, Douglas. Media spectacle. London/New York: Routledge, 2003.

LASH, Scott; URRY, John. Economies of signs \& space. London: Sage Publications, 1994.

MTUR; FGV. Proposta estratégica de organização turística: Copa do Mundo 2014 Brasil. 
ORTIZ, Renato. Mundialização e cultura. São Paulo: Ed. Brasiliense, 2003.

ROCHE, Maurice. Mega-events and modernity: olympics and expos in the growth of global culture. London/New York: Routledge, 2000.

São Paulo Turismo. Platum 2011-2014: Plano de Turismo Municipal - Cidade de São Paulo. São Paulo: São Paulo Turismo, 2010.

SASSEN, Saskia. A sociology of globalization. New York/London: W. W. Norton \& Company, 2007.

SHIM, Doobo. Hybridity and the rise of Korean popular culture in Asia. Media, Culture \& Society, London, v. 28 (1): 25-44, 2006.

STEINER, Christopher. African art in transit. Cambridge: Cambridge University Press, 1994.

TOMLINSON, Alan. FIFA (Fédération internationaled de football association). New York: Routledge, 2014.

\section{NOTAS}

1 São Paulo Turismo, empresa de capital aberto, que tem a prefeitura de São Paulo como sócia majoritária.

$2 \mathrm{Na}$ camisa do time espanhol de futebol Atlético de Madrid, por exemplo, figura atualmente a marca Azerbaijão. Após algumas tentativas, o Azerbaijão finalmente conseguiu sediar um megaevento esportivo em 2015: a primeira edição dos Jogos Europeus. As imagens da capital do Azerbaijão, divulgadas em vídeos oficiais dos Jogos Europeus, servem como exemplos dos modos de posicionar os lugares em competição: Baku foi "vendida" como cidade do consumo de bens de luxo, com hotéis de alto padrão, lojas de alta costura e gastronomia. A cidade de Baku já se havia inscrito como postulante para os Jogos Olímpicos de Verão de 2016 (concorreu com Rio de Janeiro, Madri, Tóquio, Chicago, Doha e Praga) e de 2020 (concorreu com Tóquio, Istambul, Madri, Doha e Roma), sendo derrotada em ambas as ocasiões.

3 Os esforços articulados por diferentes instâncias - estatais e empresariais em prol de projetos de internacionalização tendem a criar imagens da Coreia do Sul como sociedade globalizada. As redes de cooperações entre universidades e empresas exemplificam com alguma precisão esse panorama de elisão de antigas fronteiras, as quais foram substituídas por novos parâmetros de construção de barreiras, sobretudo com a divulgação de rankings de produção acadêmica. Algumas das principais iniciativas de internacionalização da produção acadêmica sul-coreana são o programa Global Korea Scholarship (GKS), o projeto Korea University Global e a instalação de escritórios ou campi de grandes universidades dos Estados Unidos como MIT-Korea, promovida pelo MIT International Science and Technology Initiatives (Misti) com apoio de Samsung, Google Seoul e Hyundai, e SUNY Korea no campus da Songdo Global University. 
4 Podem ser identificadas variadas iniciativas de transformar a Coreia do Sul em polo esportivo da Ásia como as etapas do circuito automobilístico de Fórmula 1 (quatro edições de 2010 a 2013), Jogos Regionais Asiáticos (1986, 2002 e 2014), Campeonato Mundial de Atletismo (2011), Copa do Mundo de futebol masculino (2002, realizada em parceria com o Japão), Jogos Olímpicos de Verão (1988), Jogos Mundiais Militares (2015), Jogos Olímpicos de Inverno (2018) e Jogos Universitários (Universiade de Inverno, 1997; Universiade de Verão, 2003 e 2015).

5 Over 100,000 fans to take to the streets to cheer for S. Korea. Yonhap News Agency, 17 de junho de 2014. Disponível em: http://english.yonhapnews. co.kr/full/2014/06/17/81/1200000000AEN20140617003700315F.html. Acesso em: 10/5/2015. Thousands Join Street Events for South Korea's World Cup Opener. The Wall Street Journal. Korea RealTime, 18 jun. 2014. Disponível em: http://blogs.wsj.com/korearealtime/2014/06/18/thousands-join-streetevents-for-south-koreas-world-cup-opener/. Acesso em: 10/5/2015.

6 A fornecedora do material esportivo da confederação sul-coreana de futebol é a Nike, principal concorrente da Adidas.

7 Adidas all in arena World Cup Campaign Day 2. Disponível em: https://vimeo. com/98936596. Acesso em: 10/5/2015.

8 AOA, Ailee, Tiny-G \& more cheer on the Korean national soccer team 'Red Devils' with World Cup support songs. Allkpop.com, 11 mar. 2014. Disponível em: www./article/2014/03/aoa-ailee-tiny-g-more-cheer-on-the-korean-national-soccer-team-red-devils-with-world-cup-support-songs. Acesso em: 10/5/2015. Red Devil 5th "We Are the Reds", iTunes. Disponível em: https:// itunes.apple.com/us/album/bulg-eun-agma5jib-we-are-reds/id876281386. Acesso em: 10/5/2015.

9 Nas emissoras sul-coreanas, K-Idols aparecem em reality shows, programas de moda e maquiagem, competições esportivas e entrevistas. Além da Korean Broadcasting System (KBS) e seu Music Bank, as emissoras MBC (Munhwa Broadcasting Corporation), SBS (Seoul Broadcasting System) e Mnet (Music Network) apresentam programas com formatos semelhantes para divulgação de lançamentos musicais. A competição musical Music Bank e seus congêneres - Inkigayo, da SBS, retransmitido como K-Pop Countdown pela One Asia TV, Show! Music Core, da MBC, M! Countdown, da Mnet - são as principais plataformas de lançamento de singles.

10 Alguns artistas são recorrentes na lista de convidados das edições do Music Bank World Tour, como a cantora Ailee. Contratada da YMC Entertainment desde 2011, empresa do cantor de trot e radialista na KBS Happy FM Tae Jin Ah, Ailee foi convidada para três edições consecutivas do Music Bank World Tour: Jacarta (2013), Rio de Janeiro e Cidade do México (2014). Nascida em 
Denver em 1989 e criada em New Jersey, desde sua transferência para a Coreia do Sul participa de diferentes programas de competição musical em emissoras sul-coreanas. Lançou seu primeiro EP em 2012 e no mesmo ano atuou em uma série dramática da KBS; dois outros minialbuns foram divulgados em 2013 e 2014. Com habilidade em diferentes idiomas, Ailee interpretou a canção turca "Üsküdar'a Gider İken" no Music Bank realizado em Istambul e "Donde voy", composta pela cantora americana Tish Hinojosa, de origem mexicana, no Music Bank realizado na Cidade do México.

11 A KBS mantém, desde 2004, um escritório nos Estados Unidos para promover a "cultura coreana" com transmissão via satélite, e realizações de eventos como LA K-Pop Festival, apresentado em 2014 no Memorial Coliseum and Sports Arena. O release da emissora a define como "janela" para a Coreia do Sul, com escritórios no Japão e nos Estados Unidos para divulgação do lançamento de novelas, seriados e outros programas televisivos.

12 Music Bank in Brazil (2014.07.15). Disponível em: https://www.youtube.com/ watch?v=FqrKZk4oCxl. Acesso em: 5/10/2015

13 A Coreia do Sul sediou em 2015 a 28a Universiade de Verão, os Jogos Universitários organizados pela International University Sports Federation (Fisu), na cidade de Gwangju. Além das competições esportivas, a $28^{\mathrm{a}}$ Universiade de Verão contou com extensa programação cultural denominada Cultureversiade, com a participação de artistas como Psy e as boy bands BTS e SHINee e os girl groups EXID, Girl's Day e 4Minute.

14 Em evento de promoção do K-Smile, realizado em novembro de 2015 com presença da presidente Park Geun-hye, a Korea Tourism Organization (KTO) divulgou Seolhyun, integrante do girl group AOA, e o ator Lee Min Ho como dupla de embaixadores da Coreia do Sul no período entre 2016 e 2018. Em 2018 os Jogos Olímpicos de Inverno serão sediados em PyeongChang, cidade a 180 quilômetros de Seul, onde foi realizada a edição de inverno dos Special Olympics World Games em 2013. O teaser de divulgação do evento evidencia quais aspectos serão apreciados pelas campanhas turísticas para os Jogos Olímpicos de Inverno no vídeo intitulado PyeongChang Awaits You: a natureza e os "5000 anos de história", pontos turísticos (praça Gwanghwamun, rio Han em Seul, templos e palácios) e eventos (Seoul International Fireworks Festival em Seul e Festival de Neve Daegwallyeong em PyeongChang). Além disso, define o vibrant lifestyle da Coreia com shoppings, gastronomia, K-Pop, Taekwondo e os eventos internacionais (os Jogos Olímpicos de 1988 e a Copa de 2002). No vídeo promocional da capital sul-coreana, divulgado em 2009, com o slogan "infinitely yours", ganham destaque a grandiosidade dos prédios e as praças do Centro da maior cidade do país, as práticas de lazer no rio Han, a estátua do herói de guerra Yi Sun-sin (liderança militar coreana no século XVI nas batalhas contra a invasão japonesa) na praça Gwanghwamun e a fonte multi- 
colorida da ponte Banpo. Nos refrões de "S.E.O.U.L (Seul Song)", cantada por integrantes de Girls' Generation e Super Junior, bandas da produtora S.M. Entertainment, é frisada a ideia de que Seul é uma cidade para encontrar a beleza do mundo, um lugar onde os sonhos podem tornar-se realidade. Para conferir o vídeo oficial de divulgação de PyeongChang 2018: PyeongChang Awaits You. Disponivel em: https://www.youtube.com/watch?v=fIL4IKMJyYs. Acesso em: 29/9/2015. Para conferir as representações sobre Seul no vídeo promocional do turismo da capital sul-coreana: SMENT. Disponivel em: https://www. youtube.com/watch?v=up6n1WrB7aE. Acesso em: 29/9/2015.

15 About Cici. Disponível em: http://cici2.g3.cc/en_greetings. Acesso em: $5 / 10 / 2015$.

Luã Ferreira Leal é doutorando no Programa de Pós-graduação em Sociologia (IFCH/Unicamp) e mestre pela mesma instituição, com bolsa concedida pela Fapesp para desenvolvimento das pesquisas. Graduado em ciências sociais pela Escola de Ciências Sociais do CPDOC/FGV.

Michel Nicolau Netto é professor do Departamento Sociologia do IFCH/ Unicamp. Doutor em sociologia pela Unicamp, com estágio de doutorado na Humboldt Universität de Berlim, tem pós-doutorado em sociologia pela Unicamp, tendo sido visiting scholar no llas/Columbia University, em Nova York, em 2014. É membro do Grupo de Estudos de Práticas Culturais Contemporâneas - Gepracc/PUC-SP, e líder do Grupo de Estudos em Pierre Bourdieu - Gebu, Unicamp. É autor dos livros Música brasileira e identidade nacional na mundialização (2009) e O discurso da diversidade e a World Music (2014). 
